\title{
Thermodynamic Studies of High-Temperature Processes in the System "Loesslike Loam - Coal - Alkaline"
}

\author{
Babaev Zabibulla Komilovich, Ermetov Amirbek Ismailovich \\ Department of Chemical Technology, Chemical-Technological Faculty, Urgench State University, Urgench City, Uzbekistan \\ Email address: \\ goodluck_0714@mail.ru (E. A. Ismailovich) \\ To cite this article: \\ Babaev Zabibulla Komilovich, Ermetov Amirbek Ismailovich. Thermodynamic Studies of High-Temperature Processes in the System \\ "Loesslike Loam - Coal - Alkaline". Modern Chemistry. Vol. 6, No. 2, 2018, pp. 20-22. doi: 10.11648/j.mc.20180602.12
}

Received: June 10, 2018; Accepted: June 26, 2018; Published: July 25, 2018

\begin{abstract}
In recent years, studies of a number of foreign scientists have been reported on the possibility of using loess loam as the main constituent of the ceramic composition in the production of clinker brick. Loess loam is considered a common raw material. In this paper, we consider the purpose, which is research on the study and development of methods that regulate the physicochemical processes occurring in the mass of loess-like loam under the influence of temperature. As a result of these studies it will be possible to intensify thermochemical processes and achieve high-quality products with minimal energy costs.
\end{abstract}

Keywords: Loess-Like Loam, Thermochemical, Alkali Oxides, Reactions, Carbon, Sodium Hydroxide

\section{Introduction}

Rapid development of construction of housing and industrial buildings and structures dictates the need to increase the output of wall materials. The wall building materials include ceramic bricks, obtained by burning in a high-temperature environment. The main cheap raw material for the production of ceramic building bricks is loess loam, whose reserves in Uzbekistan are unlimited. Loesslike loams in Uzbekistan were formed as a result of the deposition of dust brought by the wind mainly from deserts, and also there are silty deposits of various rivers carrying products of rock destruction in their waters. Under the influence of atmospheric factors, loose materials gradually disintegrated, enriching loam with finely dispersed fractions. The mineralogical composition of loesslike loams is represented mainly by quartz, carbonates, feldspars, biotite, muscovite and clay minerals. From the point of view of chemistry, loess-like loam is a ready-made mixture consisting of several active and inert components, among which there are basic, alkaline earth, alkaline oxides, as well as elements of variable valence. Under the influence of heat, there is an interaction between these substances, resulting in a stone-like body.

The purpose of our research is to study and develop methods that regulate the physicochemical processes occurring in the mass of loess-like loam under the influence of temperature. As a result of these studies it will be possible to intensify thermochemical processes and achieve highquality products with minimal energy costs.

\section{Methods}

The issues of intensification of high-temperature processes and prediction of the properties of ceramic materials in the firing process at given temperatures and holding times are a necessary task in the light of solutions to energy conservation issues. In scientific and technical and applied research, thermodynamic analysis is often used to create and select optimal technological schemes for processing raw materials, as well as for preliminary modeling of technical processes and synthesis of materials with specified physical and technical properties. The thermodynamic method of investigating high-temperature processes can provide valuable information on the possibility of purposeful behavior of various reactions, on the ways of controlling processes, on the thermal changes accompanying the reaction [1-4].

For chemical reactions taking place at $\mathrm{P}=$ const and $\mathrm{T}=$ const, according to the second law of thermodynamics, by means of which the energy possibility is determined, and the direction of the chemical reactions is expressed by the equation

$$
\Delta G_{T}^{0}=\Delta \mathrm{H}_{T}^{0}-\mathrm{T} \Delta S_{T}^{0}
$$


where, $\mathrm{T}$ is the absolute temperature ${ }^{\circ} \mathrm{K}, \Delta \mathrm{H}_{T}^{0} ; \cdot \Delta S_{T}^{0}$ - change in the thermal effect and entropy of the system under standard conditions $\left(\mathrm{T}=25^{\circ} \mathrm{C}\right.$ and $\left.\mathrm{P}=1 \mathrm{~atm}\right)$, respectively.

It is known that the thermal effect of the reaction is determined by a change in temperature in accordance with the Kirchhoff equation:

$$
\Delta H_{T}^{0}=\Delta H_{298}^{0}+\int_{298}^{T} \Delta C_{p} \cdot d T
$$

where, $\Delta H_{298}^{0}$ - the thermal effect of the reaction at standard temperature,

$\Delta \mathrm{C}_{\mathrm{p}}$ is the difference between the total equilibrium constants, by means of which the equilibrium composition of the reacting mixture can be calculated, the limiting yield of products, the direction of the reaction is determined by the equation:

$$
\lg K_{p}=\frac{-G_{T}^{0}}{2.3 \cdot R T}
$$

where $\mathrm{R}$ is the universal gas constant,

$G_{T}^{0}$ is the standard Gibbs energy.

The solution of the main problems of thermodynamic investigation of high-temperature processes in solid mixtures requires careful consideration of phase transformations of components in the temperature range under consideration and changes in entropy and heat capacity with temperature. $[5,6]$

\section{Materials}

When the system goes into a more disorderly state, the entropy naturally increases. Therefore, the term of the equation $\mathrm{T} \cdot \Delta S_{T}^{0}$, containing the entropy, always acts in such a way that as the temperature increases, the reaction proceeds in the direction associated with the increase in the amount of the liquid or gaseous phase. This explains, for example, that burning of carbon at high temperatures proceeds mainly by the equation, under any temperature conditions the reaction is accompanied by a thermal effect. This must be taken into account in the thermodynamic calculations of the reaction taking place at elevated temperatures involving carbon.

Main part. Under normal conditions, when fossil loam is fired in the temperature range $500-700^{\circ} \mathrm{C}$, dehydration occurs and the structure of minerals is destroyed. In our studies, the purpose of intensifying the firing process of raw mixtures for the production of wall ceramic bricks was modified with coke-base and sodium hydroxide. In the case of the application of a mass of simultaneously burning additive and a low-melting component, i.e. alkali, the situation is different [2]. For the purpose of decomposition of sulphate, carbonate and other salts, burnt additives play the role of a reducing agent. Some reducing agents burn out at lower temperatures than the decomposition of salts. For example, sulfates decompose at higher $\left(900^{\circ} \mathrm{C}\right)$ temperatures. To intensify the decomposition of refractory salts, a corresponding burn-out additive is necessary, the coke additive proposed is an appropriate component for these purposes [3]. For the energy evaluation of the use of this additive, it is necessary to evaluate the influence of each of its components. Therefore, the following reaction equations were computed for the calculation of $\Delta H_{T}^{0}, \Delta \mathrm{G}_{\mathrm{T}}^{\mathrm{o}}, K_{p}$.

$$
\begin{gathered}
\mathrm{Al}_{2} \mathrm{O}_{3} \cdot 2 \mathrm{SiO}_{2} \cdot 2 \mathrm{H}_{2} \mathrm{O} \rightarrow \mathrm{Al}_{2} \mathrm{O}_{3} \cdot 2 \mathrm{SiO}_{2}+2 \mathrm{H}_{2} \mathrm{O} \text { газ } \\
\mathrm{Al}_{2} \mathrm{O}_{3} \cdot 2 \mathrm{SiO}_{2} \cdot 2 \mathrm{H}_{2} \mathrm{O}+\mathrm{C}+\mathrm{O}_{2} \rightarrow \mathrm{Al}_{2} \mathrm{O}_{3} \cdot 2 \mathrm{SiO}_{2}+\mathrm{CO}_{2 \text { газ }}+2 \mathrm{H}_{2} \mathrm{O}_{\text {газ }} \\
\mathrm{Al}_{2} \mathrm{O}_{3} \cdot 2 \mathrm{SiO}_{2} \cdot 2 \mathrm{H}_{2} \mathrm{O}+\mathrm{C}+\mathrm{O}_{2} \rightarrow y-\mathrm{Al}_{2} \mathrm{O}_{3} \cdot 2 \mathrm{SiO}_{2}+\mathrm{CO}_{2 \text { газ }}+2 \mathrm{H}_{2} \mathrm{O}_{\text {газ }}
\end{gathered}
$$

In the reaction equations, the percentage of carbon and $\mathrm{NaOH}$ in the coke-alkaline additive was taken into account, with its optimal introduction in relation to the clay component of the brick raw meal [7-9].

Using the thermodynamic properties of compounds, a calculation was made of the determination $\Delta H_{T}^{0}$ of the thermal effect of the reaction (1)-(3) $\Delta G_{T}^{o}$ of the probability of flow, $K_{p}$ of the equilibrium constant in the temperature range 473-
$723 \mathrm{~K}\left(200-450^{\circ} \mathrm{C}\right)$.

\section{Results}

The thermal effect of reaction (1)-(6) with temperature changes can be calculated by the equations:

$$
\begin{gathered}
\Delta \mathrm{H}_{\mathrm{T}_{1}}^{0}=342,80 \cdot 10^{3}+\int_{298}^{\mathrm{T}}\left(49,11-89,44 \cdot 10^{-3} \mathrm{~T}+18,97 \cdot 10^{5} \cdot \mathrm{T}^{-2}\right) \mathrm{dT} \\
\Delta \mathrm{H}_{\mathrm{T}_{2}}^{0}=-50,71 \cdot 10^{3}+\int_{298}^{\mathrm{T}}\left(44,29-88,06 \cdot 10^{-3} \mathrm{~T}+23,11 \cdot 10^{5} \cdot \mathrm{T}^{-2}\right) \mathrm{dT} \\
\Delta \mathrm{H}_{\mathrm{T}_{3}}^{0}=-237,96 \cdot 10^{3}+\int_{298}^{\mathrm{T}}\left(-22,61-9,09 \cdot 10^{-3} \mathrm{~T}+13,79 \cdot 10^{5} \cdot \mathrm{T}^{-2}\right) \mathrm{dT}
\end{gathered}
$$

The equations $\Delta \mathrm{S}_{\mathrm{T}}$ for the reaction (1)-(3) have the following form:

$$
\begin{gathered}
\Delta \mathrm{S}_{\mathrm{T}}=\Delta \mathrm{S}_{298}+\int_{298}^{\mathrm{T}} \frac{\mathrm{C}_{\mathrm{P}}}{\mathrm{T}} \cdot \mathrm{dT} \\
\Delta \mathrm{S}_{\mathrm{T}_{1}}=332,19+\int_{298}^{\mathrm{T}} \frac{\left(49,11-89,44 \cdot 10^{-3} \mathrm{~T}+18,97 \cdot 10^{5 \cdot} \mathrm{T}^{-2}\right)}{\mathrm{T}} \cdot \mathrm{dT}
\end{gathered}
$$




$$
\begin{aligned}
& \Delta \mathrm{S}_{\mathrm{T}_{2}}=335,02+\int_{298}^{\mathrm{T}} \frac{\left(44,29-88,06 \cdot 10^{-3} \mathrm{~T}+23,11 \cdot 10^{5} \cdot \mathrm{T}^{-2}\right)}{\mathrm{T}} \cdot \mathrm{dT} \\
& \Delta \mathrm{S}_{\mathrm{T}_{3}}=335,02+\int_{298}^{\mathrm{T}} \frac{\left(-22,61-9,09 \cdot 10^{-3} \mathrm{~T}+13,79 \cdot 10^{5} \cdot \mathrm{T}^{-2}\right)}{\mathrm{T}} \cdot \mathrm{dT}
\end{aligned}
$$

\begin{tabular}{|c|c|c|c|c|c|c|c|c|c|}
\hline \multirow{3}{*}{ Reaction } & \multicolumn{9}{|c|}{ Temperature T, K } \\
\hline & \multicolumn{3}{|c|}{473} & \multicolumn{3}{|l|}{600} & \multicolumn{3}{|l|}{725} \\
\hline & $\Delta \boldsymbol{S}_{T}^{\mathbf{0}}$ & $\Delta G_{T}^{0}$ & Кр & $\Delta \boldsymbol{S}_{T}^{\mathbf{0}}$ & $\Delta G_{T}^{0}$ & Кр & $\Delta \boldsymbol{S}_{T}^{\mathbf{0}}$ & $\Delta \boldsymbol{G}_{T}^{\mathrm{o}}$ & Kp \\
\hline 1 & 326.3 & 193.35 & $4.5 \cdot 10^{-22}$ & 323.5 & 154.61 & $3.5 \cdot 10^{-14}$ & 319.9 & 116.05 & $4.4 \cdot 10^{-9}$ \\
\hline 3 & 191.7 & -322.8 & $4.4 \cdot 10^{35}$ & 195.9 & -351.7 & $4.1 \cdot 10^{30}$ & 202.8 & -379.5 & $2.2 \cdot 10^{27}$ \\
\hline
\end{tabular}

Table 1. The value of $\Delta S_{T}^{0}, \mathrm{~J} / \mathrm{mol}, \Delta G_{T}^{\mathrm{o}}, \mathrm{kJ} / \mathrm{mol}, K_{p}$ as a function of temperature $T$.

\section{Discussion}

The results of the calculations $\Delta H_{T}^{\mathrm{o}}$ indicate that the reaction (1) dehydration of kaolinite without additives is an endothermic process. The introduction of an additive containing carbon, the same reaction $(2,3)$ dehydration already takes place with the release of heat $\Delta H_{T}^{0}<0$, i.e carbon in the presence of oxygen burns, and this heat is expended on the destruction of the crystal lattice of minerals. The amount of heat released with a sufficient amount of carbon is for the reaction (2) 46.03-79.88 kJ/ mol. The presence of alkalis intensifies many high-temperature physico-chemical synthesis processes, including the dehydration of clay minerals, and with increasing temperature, the amount of heat liberated increases and reaches $84.48 \mathrm{~kJ} / \mathrm{mol}$ at $725^{\circ} \mathrm{K}$. The introduction of a complex additive containing carbon and sodium hydroxide further accelerates the process of dehydration of kaolinite, the amount of heat released is in the temperature range 473$725^{\circ} \mathrm{K} 80.25-119 \mathrm{~kJ} / \mathrm{mol}$, and taking into account the ratio of carbon, $\mathrm{NaOH}$, both separately and in the complex, it is possible to shift the equilibrium from left to right and the possibility of the dehydration reaction of kaolinite in the temperature range under consideration is present $\left(\Delta G_{T}^{0}<0\right.$, a $\mathrm{K}_{\mathrm{p}}>1$ ).

Moreover, as the temperature increases, $\Delta G_{T}^{\mathrm{o}}$ decrease and $\mathrm{K}_{\mathrm{p}}$ increase, which indicates an increase in the stability and stability of the system [10-12].

\section{Conclusion}

Thus, the possible chemical interactions between minerals of loess-like loam have been theoretically studied, the medium of which is given priority to the decomposition of kaolinite. To intensify the decomposition process of refractory minerals, it is recommended to use an alkali additive in an amount of up to $5 \%$, with a weight ratio of coal: alkali-1:1.

Such an approach not only improves the rheological properties of the raw composition for the production of highquality bricks, but also allows the dehydration of clay minerals to be shifted to lower temperatures, and the amount of heat released in the temperature range $473-725^{\circ} \mathrm{K}$ will lead to significant savings in thermal energy.

\section{References}

[1] Budanov V. V. Chemical thermodynamics SPb-M-Krasnodar: Lan. 2016.-318s.

[2] Efimov K. A. Electrosurface and rheological properties of clay materials with complex additives: dis... candidate of technical sciences 02. 00. 11. Belgorod, 2007. 148.

[3] Chemical products from coal/ S. N. Baranov, V. I. Saranchuk, V. A. Sapunov and others. Kiev: Nauk. dumka, 1983. 116s.

[4] Goncharov Y. I., Doroganov EA, Zhidov K. V. Mineralogy and features of rheology of clays of kaolinite-illite composition// Glass and ceramics. 2003. № 1. Pp. 19-23.

[5] Chistyakov B. E., Bedenko V. G., Nichikova T. N. Additives of carbon alkaline reagent and rheological properties of raw sludge// Cement. 1989. № 11. Pp. 17-18.

[6] Panova O. A., Ivleva I. A., Besedin P. V. Investigation of the structural-rheological properties of the composition in the presence of an alkali-reagent// Cement and its application. 2012. №5. Pp. 94-98.

[7] P. V., Panova O. A., Ivleva I. A. Techniques, patterns and mechanisms of energy conservation on the base of using of plasticizing agents in the technology of making of the cement clinker// Word Applied Sciences Journal. 25 (1): 83-91. 2013.

[8] Babushkin V. I., Matveyev G. M., Mchedlov-Petrosyan O. P. Thermodynamics of silicates 4 th ed., Pererab. and additional. Moscow: Stroiizdat, 1986. 408 p.

[9] Eitel V. Physical chemistry of silicates. Moscow: Publishing House of Foreign Literature, 1962. 1056 p.

[10] Prigogine I., Defay R. Chemical Thermodynamics. Novosibirsk: Science, Siberian Division, 1966. 512 p.

[11] Guzman I. Y. Chemical technology of ceramics. Textbook. manual for universities. M.: OOO RIF "Stroimaterialy", 2003. $496 \mathrm{p}$.

[12] Besedin P. V., Ivleva I. A., Mospan V. I. Heat-efficient wall material// Glass and ceramics. 2005. № 6. P. 24-25. 